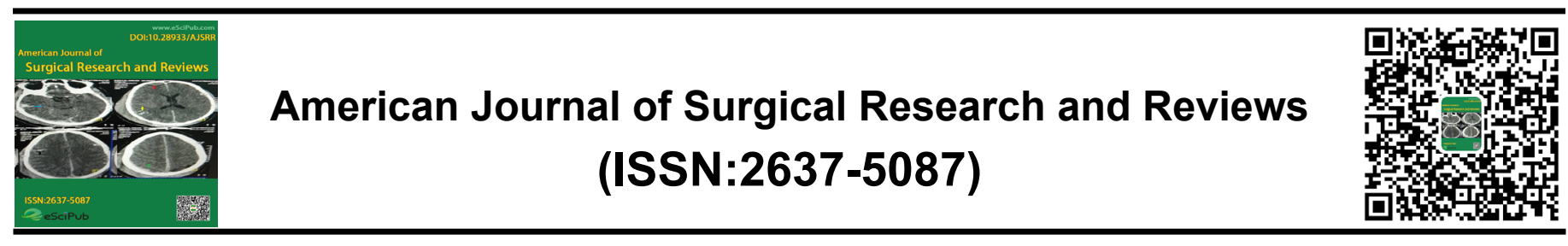

\title{
Facial Fat Grafting in reconstructive maxillofacial surgery
}

\author{
Luigi Clauser, MD, DMD ${ }^{1 *}$, Floria Bertolini, MD $^{2}$ \\ ${ }^{1}$ Unit of Maxillo-Facial Surgery, Istituto Stomatologico Italiano, 20122 Milano, Italy. \\ ${ }^{2}$ Dermatological Clinic, Scrovegni Med.Srl, 35131 Padova, Italy.
}

\begin{abstract}
Aim: Facial Fat Grafting(FFG) was first described in the early 20th century but for many years remained a relatively underused technique due to the unreliability of long-term volume expansion and retention. FFG was initially used as a technique to improve facial aesthetics. Over the years the technique has evolved into more complex reconstructive and regenerative procedures and new clinical applications.
\end{abstract} genital and other postsurgical volume deficits. a low complication rate.

Methods: In the last two decades the indications of FFG have been extended into cranio-maxillofacial reconstructive surgery. This includes post-traumatic soft tissue defects, aesthetics,con-

Results: While several approaches were suggested for fat harvesting and grafting, the results were rather unsatisfactory due to the degeneration of many adipocytes that occurred during these manipulations. The technique of autologous fat transfer has then been perfectioned becoming an augmentation-regenerative process that can be used to treat a wide range of difficult and challenging reconstructive problems. The procedure described herein has been performed in different patients with various pathology sequelae with sactisfactory morpho-aesthetic results and

Conclusion: FFG can be used in any facial area where is lack,of soft tissue or where there is scarring,producing natural and long-lasting results. Mesenchymal stem cells represent a great tool in regenerative medicine because of their ability to differentiate into a variety of specialized cells. However more definitive studies are still needed in order to answer specific questions regarding the best technique to be used and the role of ADSC's. Clinical cases with volume paucity or deficiencies are presented with a long-term outcome in augmentation and regeneration.

Keywords: Facial fat grafting; Facial augmentation; Adipose tissue; Facial reconstruction; Stem cells; Regenerative medicine; Tissue engineering

*Correspondence to Author:

Prof. Luigi Clauser

Unit of Maxillofacial Surgery, Istituto Stomatologico Italiano, Via Pace, 21 -20122 Milano, Italy

Ph. +3902541761

How to cite this article:

Luigi Clauser, Floria Bertolini. Facial Fat Grafting in reconstructive maxillofacial surgery. American Journal of Surgical Research and Reviews, 2021; 4:11.

\section{eScîPub}

eSciPub LLC, Houston, TX USA. Website: https://escipub.com/

By using the site/services, you are agreeing to our Policies:

https://escipub.com/terms-privacypolicy-disclaimer/

AJSRR: https://escipub.com/american-journal-of-surgical-research-and-reviews/ 


\section{INTRODUCTON}

Correction of facial and maxillofacial defects using FFG was first reported at the end of the 19th century. Some physicians had used fat grafts since 1893 but with results that were uncertain and depended largely on the technique being used. In the early 20th century many reports described tissue augmentation using various injectable fillers such as rubber latex, gutta-percha, paraffin, collagen, Gore-Tex, silicon, gold and, lately, polylactic acid and Bio-Alcamid [1]

In 1991 the American Sydney R. Coleman coined the term Lipostructure $\AA$ and improved the technique by concentrating awareness on the face and considering that fat was an ideal filler with natural and stable properties which did not cause the complications of earlier fillers ${ }^{[2]}$. Different from other FFG techniques, the Coleman's procedure is unique because it allows for a delicate aspiration that does not damage the fragile adipocytes, for the purification of the fat cells, and for the reinsertion of fat using micro-injections to redefine facial contours and create a more harmonious and esthetically appealing proportions of the face ${ }^{[3,4]}$.
Human adipose tissue represents a rich source of mesenchymal stem cells because they exhibit multilineage potential and secrete angiogenic and antiapoptotic factors. ${ }^{[5-6-7]}$

FFG is best used for restoration and reconstruction of facial soft tissue after damage due to tumor resection, Parry-Romberg syndrome and scleroderma, correction of congenital abnormalities and clefts, orbital and periorbital surgery, facial palsy, burns, and scars. ${ }^{[8-9-10-11]}$

Rejuvenation of the face with FFG is also used in areas such as the forehead, nose, lips, chin, zygomas, mandible, jaw line.

\section{METHODS}

\section{Surgical technique and patient's selection}

Preoperative planning comprises a photographic study using the guidelines of Sydney Coleman [3]. Colored pencils are used on the photographs, a topographical map is delineated to mark the areas to be injected, those not to be injected, and, if necessary, those from which excessive fat tissue needs to be removed. These markings are then duplicated on the patient's face before surgery (Figure 1).

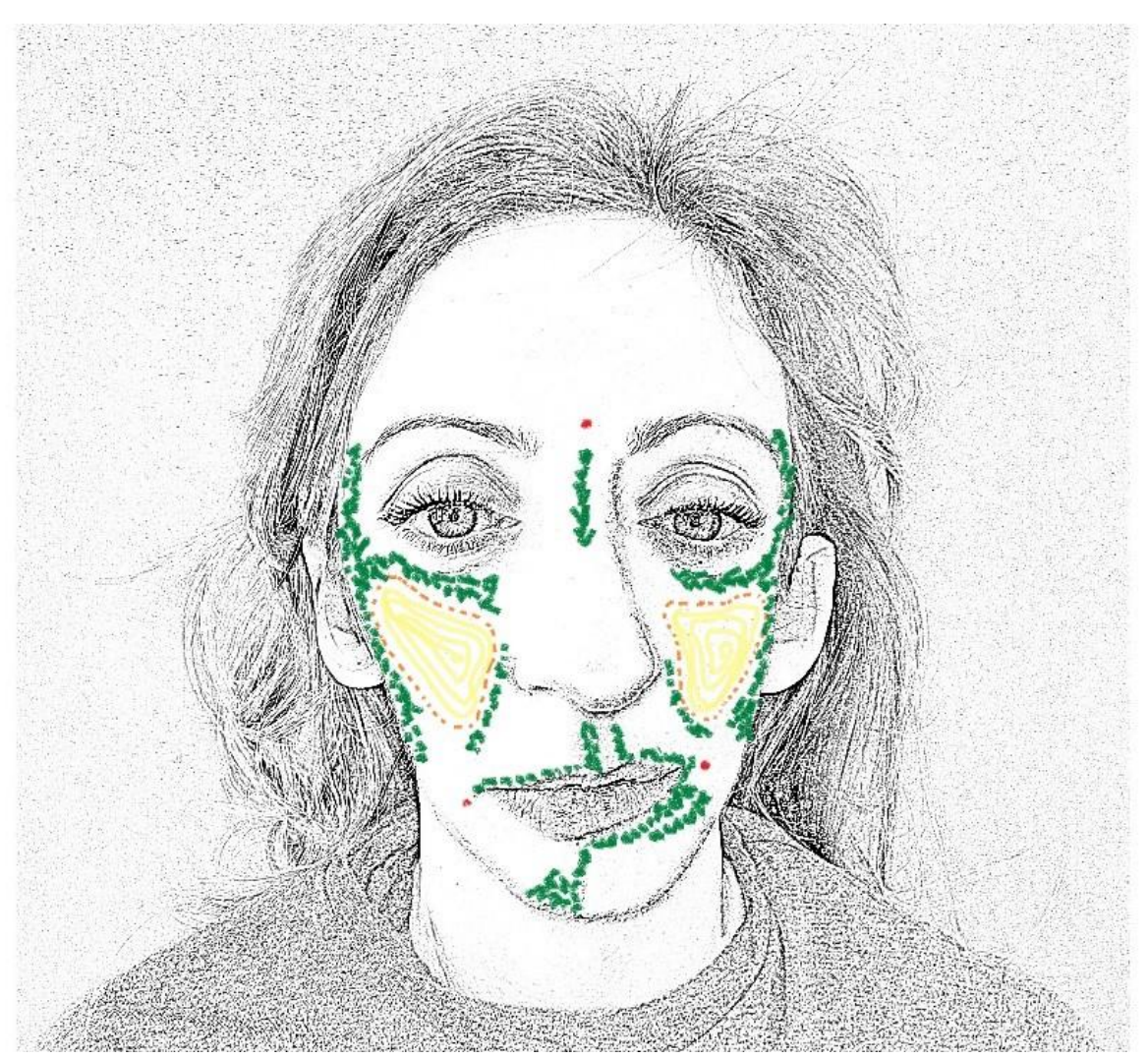

Figure 1 Facial drawing sketch:

planning and topographical map with different colours of the facial areas to be fat grafted 
The more commonly used donor sites are the trochanteric region, flanks, periumbilical area, inner thighs and knees. Instead, the buttocks are typically the preferred donor site in children and slim patients. The procedure is performed under general or local anesthesia with light sedation. Using a very thin liposuction cannula attached to a 10-mL Luer-Lock syringe for suction the fat is then aspirated. During fat removal, caution is taken to minimize any mechanical damage to the adipocytes. After the fat is removed, each $10 \mathrm{~mL}$ syringe is placed carefully into a sterilized sleeve in a sterilized central rotor of a centrifuge and is spun for 3 minutes at approximately 1,300 rpm. The fat separates into three layers. The top layer consists predominantly of oil from ruptured parcels of fat, the bottom layer of blood, and the middle layer of usable subcutaneous tissue. The oil of the top layer is decanted, while the dense lowest layer is drained. The refined fat parcels are then transferred to a 1-mL syringe and are-stratified into the areas that need to be improved, operating from the underlying bone up to the surface of the skin in a fan-like pattern.

Cannulas differing in top shape, diameter, length, and curvature can be used. Using blunt cannulas allows to place fat parcels more stably and with minimal trauma. Nonetheless, less blunt cannulas may offer more control to the surgeon regarding the placement of fat in the immediate subdermal plane, in fibrous tissue, as well as in scars. A cannula with pointed or sharp tips is used to release scar adhesions. Only as the cannula is withdrawn should the fatty tissue be injected(Figure 2).

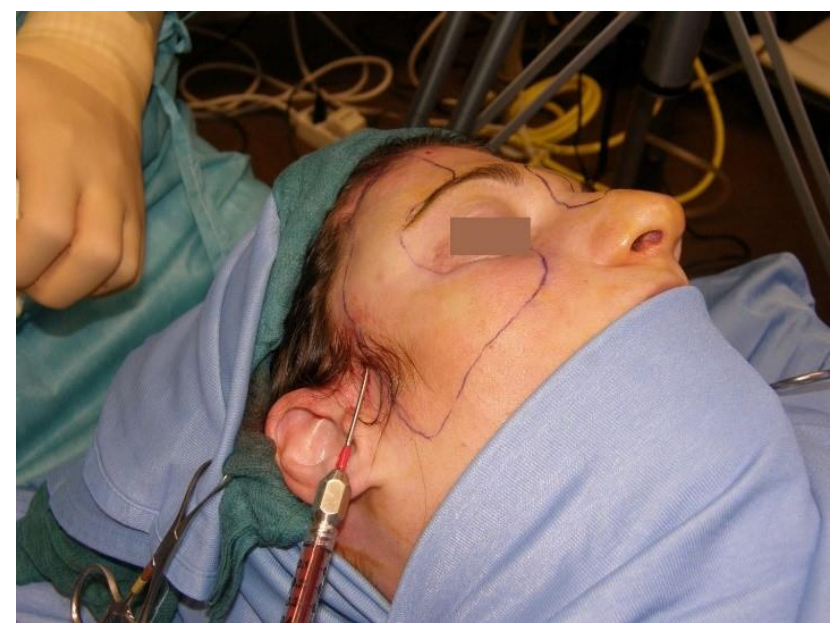

Figure 2 Intraoperative view: facial fat injection with a Coleman's cannula.

The borders of the area to be injected are delineated with a pencil.

The fat is layered linearly into the area that needs to be improved, working from the underlying bone up to the surface of the skin so as to create a three-dimensional grill in a fan shape. The largest amount of tissue to be deposited with each single withdrawal of a cannula is $1 / 10$ $\mathrm{mL}$, but in other areas as for example the eyelid, the largest amount should be between 1/30 and $1 / 50 \mathrm{~mL}$ per each withdrawal.

A single-step correction, using additional fat tissue, can cause reduced vascularization and greater reabsorption, especially in areas covered by a thin layer of soft tissue such as the maxillofacial area. For infiltration of microfat and nanofat, smaller gauge cannulas and needles should be used. Sharp needle intradermal fat grafting and disposable equipments are also available. FFG allows the fat to be carefully layered into minuscule strands creating a large surface area of contact with the augmented site, and this ensures that nutrition can be exchanged through capillaries in the enveloping tissue. This is essential for the fat to survive.

\section{Postoperative care}

After surgery compression dressings are applied around the infiltrated areas (Figure3) and the patient wears an abdominal binder if the fat is harvested from the abdomen. 


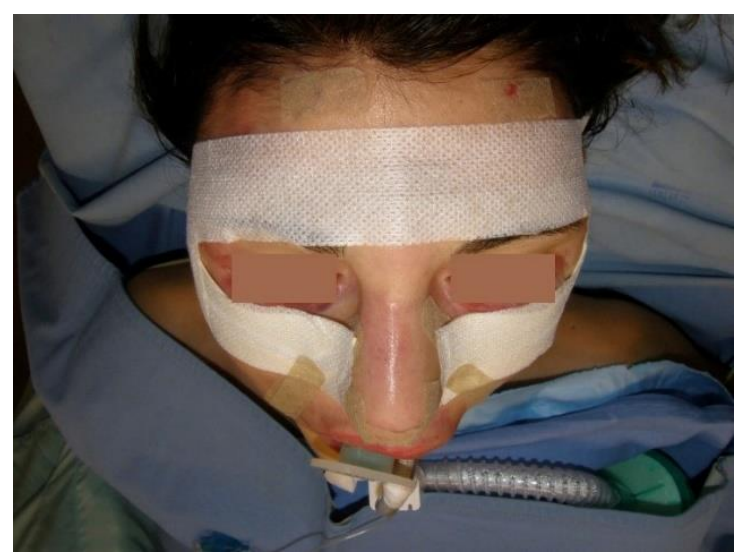

Figure 3 After the injection,

a special facial dressing with microfoam tape,and steri-strips imobilizes the fat graft for a few days.

Ice packs are applied continuously on all the grafted areas for 24-36 hours. Postoperative cares involve use of antibiotics for several days, anti-inflamatory therapy and massage of the donor area to relieve swelling and bruising. Patients must be informed that postoperative swelling can last for 2 to 3 weeks. Recovery time and downtime depend on the extent of the procedure. The body slowly absorbs the fat, although the amount of absorption is variable and frequently unpredictable. However, this percentage varies from patient to patient. If a significant amount of fat is reabsorbed, another or more procedures, serial fat grafting, may be needed to achieve the final result ${ }^{[11]}$.

When dealing with craniofacial deformities, one must bear in mind that patients have altered growth potential. Fat reabsorption is higher in these patients compared with others, and FFG should be done as many as 3 to 4 times to improve the final result, at an interval of 5-7 months.

\section{Contraindications}

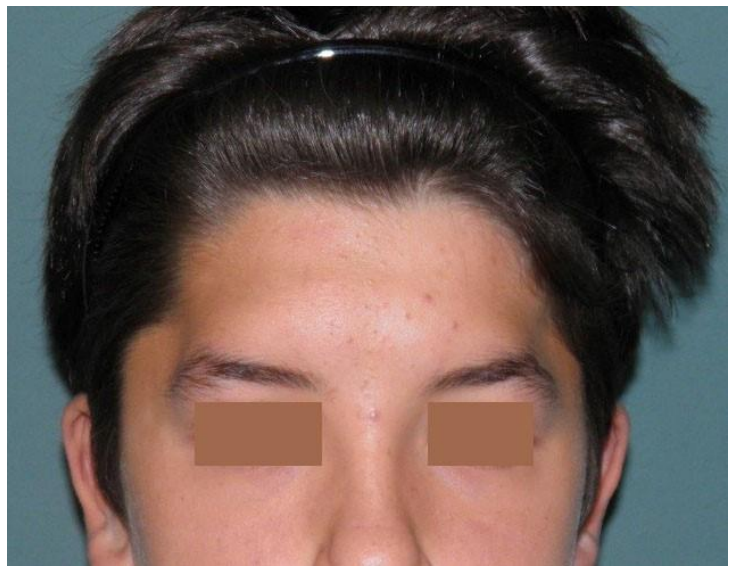

Fat grafting is definitely contraindicated in some patients because of a high risk of complications or because it may be life threatening. These include: coagulation and lipid metabolism disorders, nutritional problems, severe chronic disease state, immune status, acute infections or organ failure, cancer-chemotherapy, history of deep vein thrombosis, or pulmonary embolus.

\section{RESULTS}

Originally FFG was proposed as a way of improving facial esthetics but recently its application has been extended to more complex reconstructive procedures.

The biocompatibility of FFG easily adapts to the growth of the face over time. Compared with many other alloplastic materials, it has lower morbidity. Considering that other materials often lead to foreign body reactions, FFG is the ideal tool for resolving localized tissue atrophy, loss of substance caused by trauma and by post tumor and congenital complex craniofacial anomalies, burns, scars and hemifacial atrophy (Figures.4,5,6,7,8).

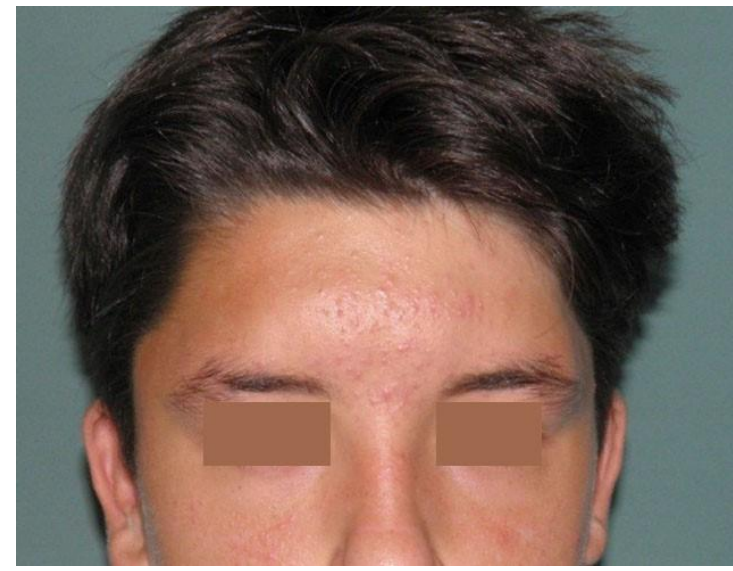

AJSRR: https://escipub.com/american-journal-of-surgical-research-and-reviews/ 
Figure $4 \mathrm{~A}, \mathrm{~B}$

(A) Bitemporal hourglass deformity after craniofacial surgery for a congenital deformity.

(B) The result after entire forehead lipostructure in3 stages with evident volume-increasing effect
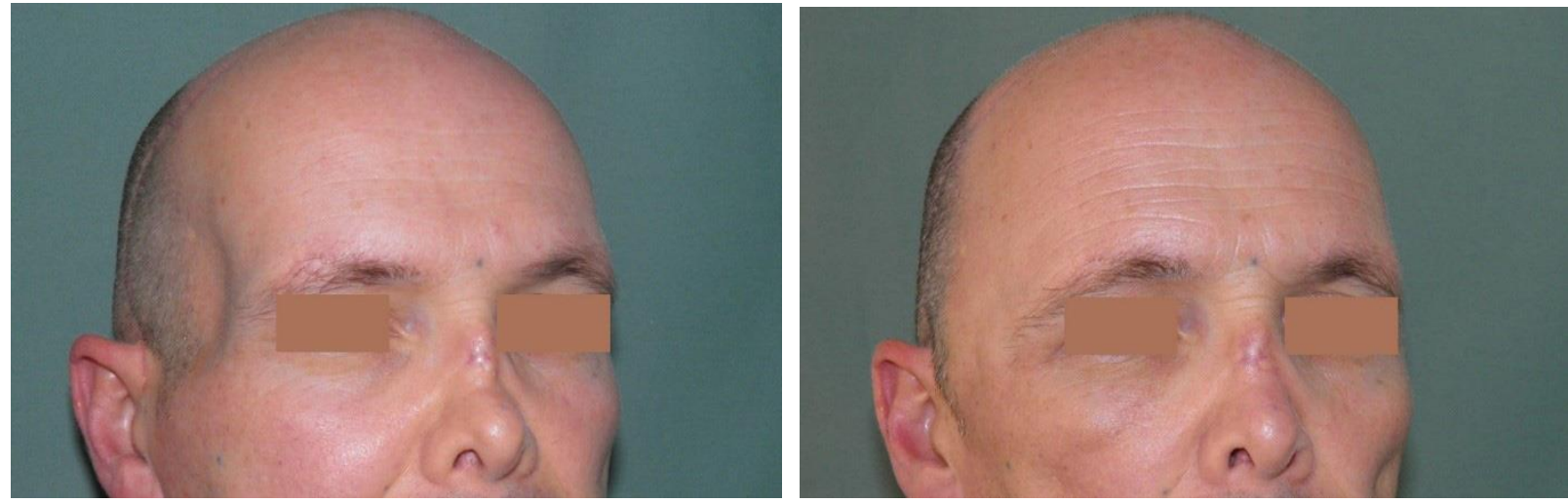

Figure $5 \mathrm{~A}, \mathrm{~B}$

(A) Right temporal hollowness after intraoral rotation of the temporalis muscle to repair a wide palatal defect with oroantral fistula due to a non-Hodgkin lymphoma. (B)The temporalis fossa after 2 serial lipostructure procedures
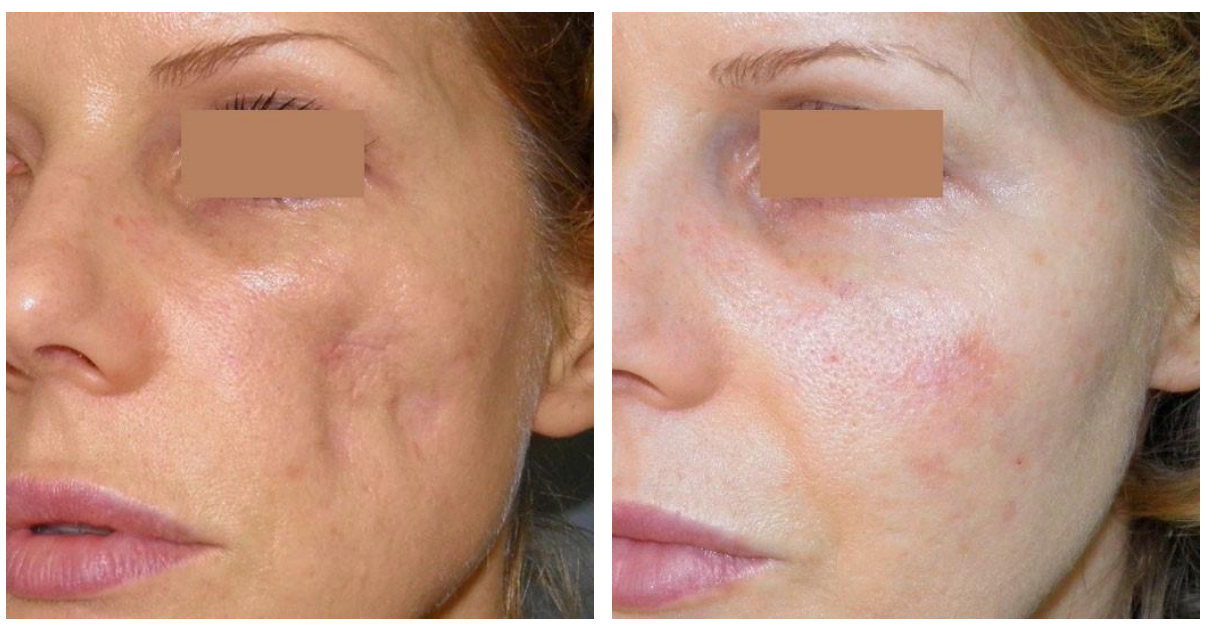

Figure 6 A, B

(A)Acquired deformity and severe facial scar after removal of a bioalcamid granuloma.

(B)The filling and regenerative effect can be seen after 3 serial fat grafting procedures
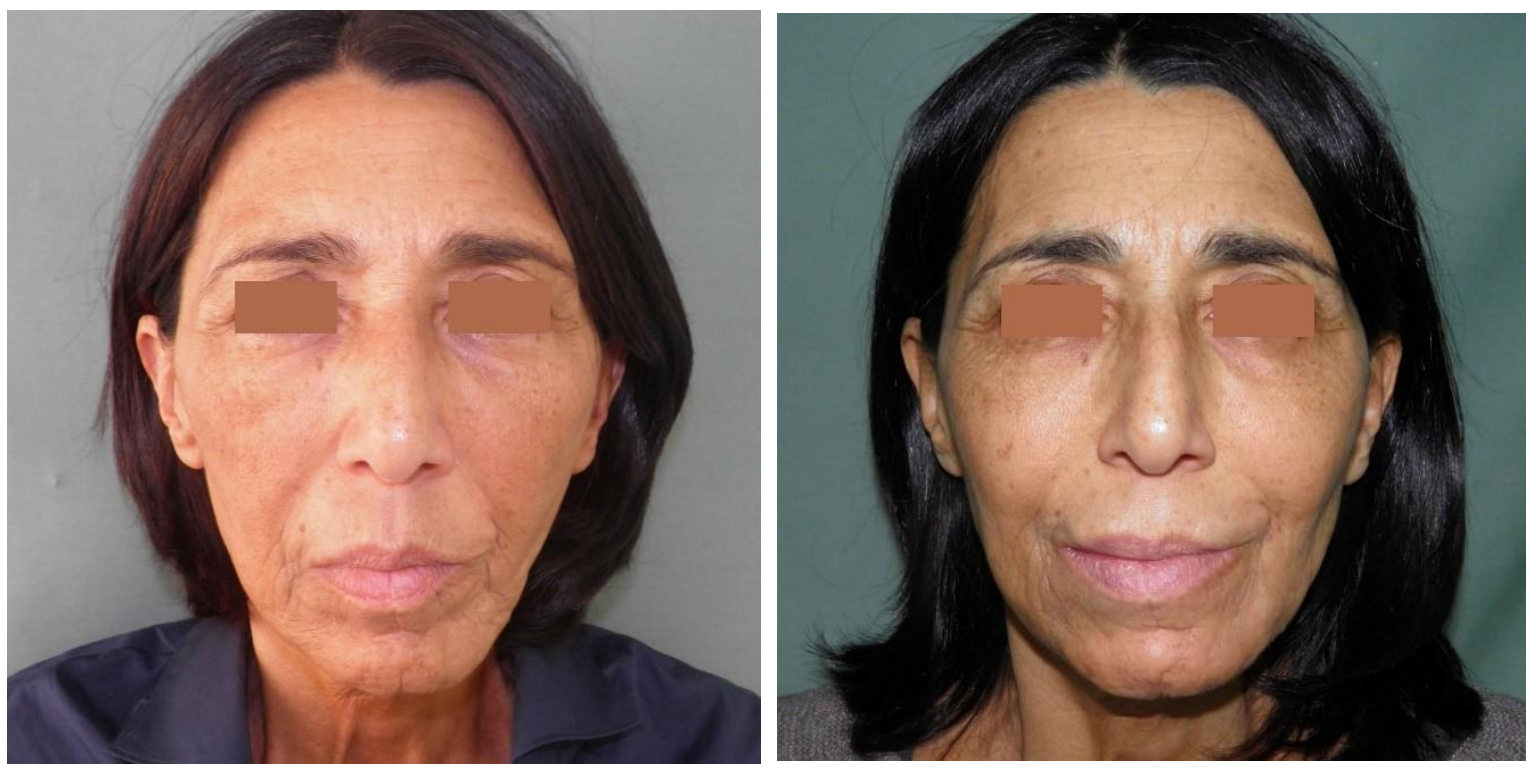

Figure $7 \mathrm{~A}, \mathrm{~B}$

(A)Left facial deformity sequelae of tongue carcinoma and radical neck dissection.

(B)Final result after total bilateral facial lipostructure with regenerative effects

AJSRR: https://escipub.com/american-journal-of-surgical-research-and-reviews/ 

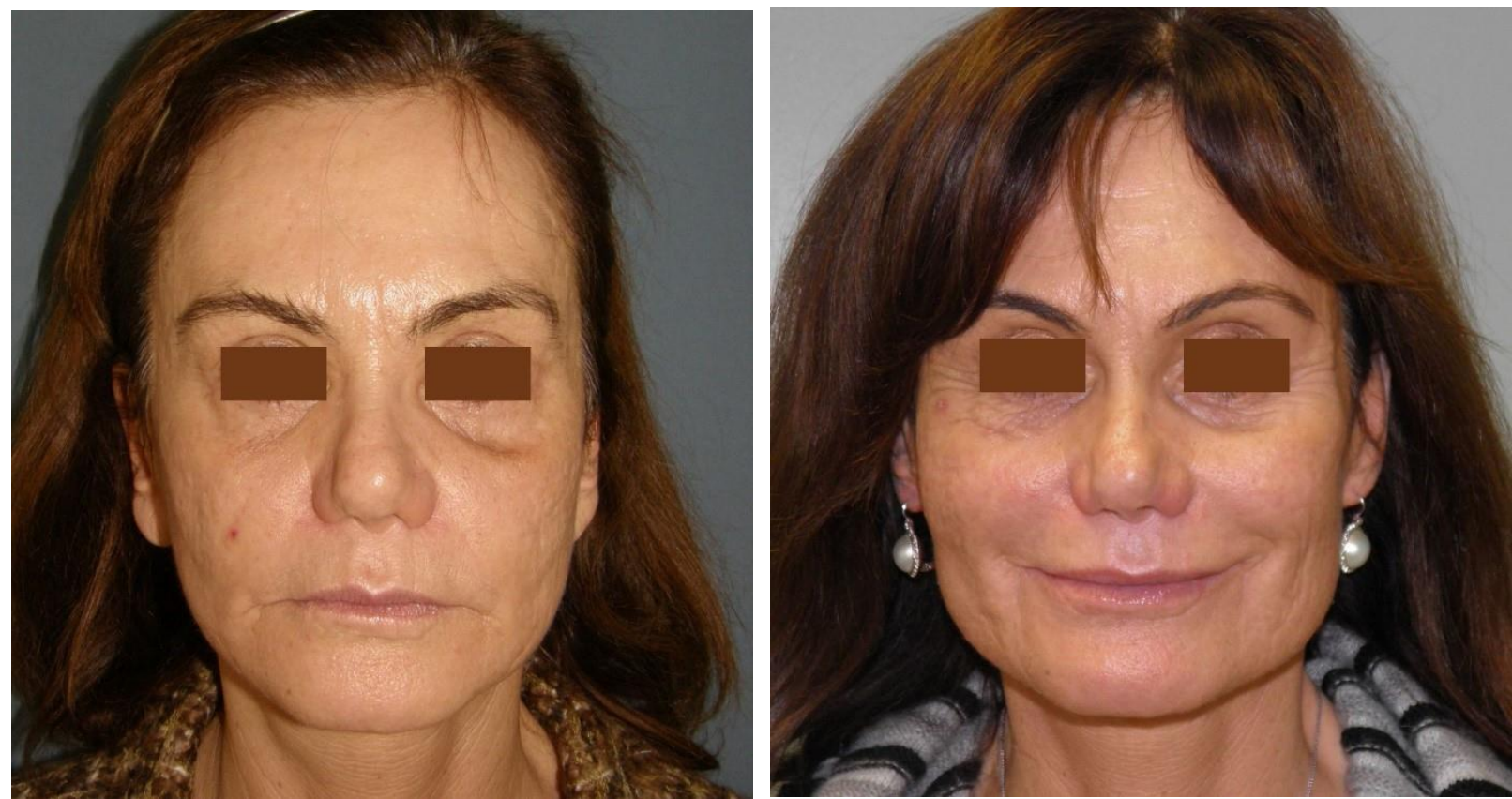

Figure 8 A, B

(A) Precocious aging face after maxillofacial complex trauma.

(B) After 3 serial autologous fat transfers: midface, inferior orbital rims, perioral area and lips, jawline

Adipose tissue can be purified in four main ways: centrifugation, filtration, decantation, and washing. Centrifugation can be compared with other techniques such as percolator and decantation; nonetheless centrifugation seems to be the best way to purify adipose tissue, since it involves no deterioration or injury to the adipocytes and since it increases fat density by eliminating red blood and cellular debris.

This technique does not affect the cellular structure, and involves no difference in cellular structures between centrifuged and non-centrifuged adipose cells. More than $90 \%$ of adipocytes survive and have normal enzyme activity using a blunt cannula and centrifugation

In craniofacial and maxillofacial surgery, FFG is a useful technique because there is minimal risk in obtaining it in relatively large quantities of fat. Even though this procedure is safe, complications may arise, the most of which are underover-correction, lumps and bumps, seroma, fat migration, damage to underlying structures, infection, and ischemic necrosis. In a very limited number of cases fat embolism has been reported. Using vasoconstrictors at the recipient site the possibility of fat emboli via the ophthalmic artery and internal carotid is reduced. Most dangerous areas are the glabella, dorsal nose, naso-labial folds [12].

Specific applications of FFG are for recalcitrant ectropion, anopthalmic socket, orthognathic surgery, and scarring or burn wounds. Ectropion (post-trauma, congenital, post aesthetic surgery) constitutes a challenging situation. Many successful and unsuccessful techniques have been reported. The basic issue with ectropion is that it involves a shortage of skin, muscles, and internal lamellae. To rebuild the internal lamella, palatal mucosal graft may be very useful but i cannot restore the skin and the orbicularis muscle. In a second stage, one can combine the lengthening of the internal lamella with micro droplets of fat. The result is a lengthening of the lower eyelid associated with an improvement in volume and texture.

FFG is atruly pearl for treating the anophtalmic socket syndrome. In the so-called post-enucleation socket syndrome, a lack of soft tissue may occur, even after placing an endo-orbital implant. The appearance may be enhanced by injecting both the intraconal space and the sulcus on the upper eyelid ${ }^{[9]}$.

FFG in orthognathic surgery represents a complimentary procedure. It is widely known that 
orthognathic surgery shifts the skeletal bases (maxilla, mandible, and chin). After orthognathic surgery FFG can correct the dysaesthetic contour irregularities intrinsic to skeletal osteotomy movements and advancements. These residual morpho-aesthetic disharomonies are particularly troubling when osteotomies are performed for purely aesthetic reasons (Figure 9). In orthognathics FFG of the periorbital area, zygomas, upper and lower maxilla and chin allows for more consistency and lightness of the face ${ }^{[8]}$.
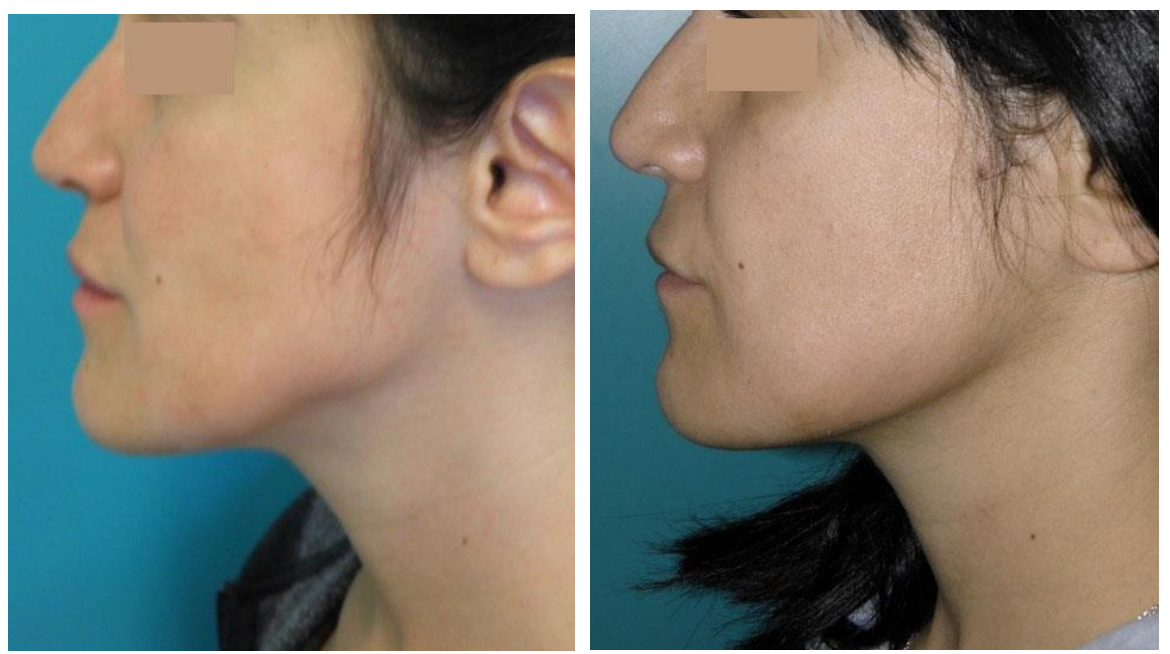

Figure $9 \mathrm{~A}, \mathrm{~B}$

(A)Lower bord mandibular residual disharmony with bony-steps after orthognathic surgery.

(B)Result after one fat transfer procedure

Various studies have shown that human adipose tissue is a rich source of mesenchymal stem cells, ADSC's, with multi-lineage potential and secretion of angiogenic and antiapoptotic factors [5.7]. Adipose-derived stem cells, previously called adipose-derived stromal cells or adiposederived regenerative cells, are isolated from the vascular stromal component of lipoaspirate. A typical lipoaspirate is composed of mature adipocytes, extracellular matrix, ADSC's, endothelial cells, and mural cells (pericytes and vascular smooth muscle cells). When the nonbuoyant cellular fraction is enzymatically digested, it forms the stromal vascular fraction containing ADSC's, vascular progenitor cells, pericytes, and endothelial cells. Even though ADSC's originally consist of mesodermal cells under the appropriate conditions they can differentiate into multiple lineages of adipogenic, osteogenic, chondrogenic, myogenic, cardiomyogenic, and neurogenic cells. Recently, studies have also shown that ADSC's are capable of differentiating into tissues of ecto and endodermal lineages such as hepatocytes and neural endothelial epithelial, and pancreatic cells. There is evidence that stem cells help in the restoration of tissue vascularization and organ function. In regenerative medicine, adipose tissue is thus potentially clinically useful for cellular therapy, tissue engineering, and gene transfer applications.

Rigotti et al demonstrated the therapeutic efficacy of ADSC's in the treatment of radiationinduced damage by replacing impaired tissue with reconstructed normal tissue ${ }^{[4]}$.

Adipose-derived stem cells may be taken into consideration in the treatment of neurologic or various other types of disorders, comprising maxillofacial deformities. In our experience all the different operations using FFG have produced sactisfactory aesthetic, morphologic and functional rehabilitation of reconstructed areas.

\section{DISCUSSION}

FFG introduced as a way of improving facial esthetics, has evolved in recent years into more complex lipostructure and reconstructive procedures.

Fat grafting should be part of the armamentarium of the surgeon not only as an ancillary tool, but also as a basic complementary reconstructive way for stimulating soft tissue repairing and 
regeneration [13,14].

Today, tissue engineering and regenerative medicine are a multidisciplinary science that is evolving along with biotechnological advances. The proposed uses for ADSC's in tissue repair-regeneration are quite impressive. Recent works on ADSC's would suggest that this adult stem cell might prove to be an equally powerful tool in treating congenital and acquired disorders. However, the availability and the processes for obtaining stem cells remain a challenge for both surgeons and scientists pursuing regenerative medicine and therapy. The future will be shaped by research, laboratory and education.

\section{DECLARATIONS}

\section{Authors' Contribution}

Contributed equally to the drafting of manuscript, data collection and analysis:

Luigi Clauser, Floria Bertolini

\section{Availability of data and materials}

Not applicable

\section{Financial support and sponsorship}

None

\section{Conflicts of interest}

All Authors declared that there are no conflicts of interest

\section{Ethical approval and consent to participate}

Not applicable

\section{Consent for publication}

Written informed consent was obtained for all patient images.

\section{REFERENCES}

[1] Coleman SR. Facial recontouring with lipostructure. Clin Plast Surg, 1997;24(2):347-367 PMID: 9142473

[2] Coleman SR. Structural fat grafts: the ideal filler? Clin Plast Surg, 2001;28(1):111-119 PMID: 11248861

[3] Coleman SR, ed. Structural Fat Grafting. Saint Louis, MO: Quality, Medical Publishing Inc; 200 pp 93-112

[4] Rigotti G, Marchi A, Sbarbati A. Adipose-derived mesenchymal, stem cells: past, present, and future. Aesthetic Plast Surg 2009; 33(3):271-273 DOI: 10.1007/s00266-009-9339-7

[5] Strem BM, Hicok KC, Zhu M, et al. Multipotential differentiation of adipose tissue-derived stem cells. Keio J Med 2005;54(3):132-141PMID: 16237275, DOI: 10.2302/kjm.54.132
[6] Fraser JK, Wulur I, Alfonso Z, Hedrick MH. Fat tissue: an underappreciated source of stem cells for biotechnology. Trends Biotechnol 2006; 24(4):150-154, PMID: 16488036 DOI: 10.1016/ j.tibtech. 2006.01.010

[7] Moseley TA, Zhu M, Hedrick MH. Adipose-derived stem and progenitor cells as fillers in plastic and reconstructive surgery. Plast Reconstr Surg 2006;118(3, Suppl):121S-128S PMID: 1693655 1 DOI: $10.1097 / 01 . p r s .0000234609 .74811 .2 e$

[8] Clauser LC, Tieghi R, Galiè M, Carinci F. Structural fat grafting: facial volumetric restoration in complex reconstructive surgery. J Craniofac Surg 2011;22(5):1695-1701 PMID: 21959415 DOI: 10.1097/SCS.0b013e31822e5d5e

[9] Clauser L, Sarti E, Dallera V, Galiè M. Integrated reconstructive strategies for treating the anophthalmic orbit. J Craniomaxillofac Surg 2004; 32(5):279-290, PMID: 15458669 DOI: 10.1016/ j.jcms.2004.04.010

[10] Clauser L et al. Fat grafting in Soft Tissue augmentation, Springer-Verlag London Ltd., part of Springer Nature 2020M. Perry, S. Holmes (eds.), Atlas of Operative Maxillofacial Trauma Surgery, pp 237-250

https://link.springer.com/book/10.1007\%2F9781-4471-5616-1, 2020

[11] Clauser L optimizing maxillofacial and craniofacial results. In: Coleman SR, Mazzola RF, eds. Fat Injection From Filling to Regeneration. Saint Louis, MO: Quality Medical Publishing Inc; 2009: pp 475-500

[12] Yoshimura K,Coleman SR. Complications of fat grafting. How they occur and how to find, avoid, and treat them. Clin Plastic Surg 2015; 42:383 DOI: 10.1016/j.cps.2015.04.002.

[13] Clauser L, Ferroni L, Gardin C,et al. Selective augmentation of stem cell populations in structural fat grafts for maxillofacial surgery. PLoS One. 2014 Nov 6;9(11) PMC422876, DOI: 10.1371/journal.pone.0110796

[14] Clauser L., A.Lucchi,I.Tocco-Trussardi et al.Autologous fat transfer for facial augmentation and regeneration. Role of mesenchymal stem cells.In: S.C Bagheri,H.A,Kahan,B.Bohli Editors. Fat grafting for aesthetic facial surgery. Atlas of the Oral and Maxillofacial Surgery Clinics of North America.Elsevier,March 2018.pp 25-32.

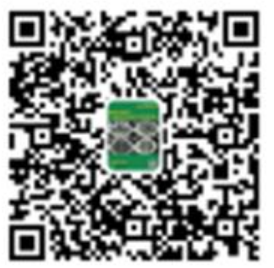

